
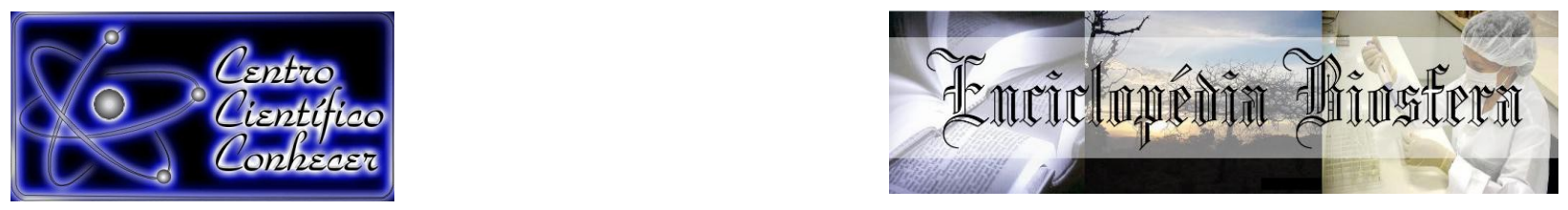

\title{
INCIDÊNCIA DE DOENÇAS FÚNGICAS NO MARACUJAZEIRO (Passiflora edulis sp.) EM PROPRIEDADES FAMILIARES NO MUNICÍPIO DE ALTA FLORESTA - MT
}

\author{
Mozarte Santos Santana ${ }^{1}$, Lucas Santos Santana², Oclizio Medeiros das Chagas \\ Silva ${ }^{3}$, Linda Mara Alvino dos Santos Ximenes ${ }^{4}$ \\ 1. Doutorando em Agroquímica na UFLA, Departamento de Química, \\ Lavras-MG, Brasil. (mozartesantana@outlook.com) \\ 2. Mestrando em Engenharia Agrícola na UFLA \\ 3. Mestrando em Engenharia Florestal na UFLA \\ 4. Graduada em Biologia pela UNEMAT
}

\section{Recebido em: 06/04/2018 - Aprovado em: 10/06/2018 - Publicado em: 20/06/2018} DOI: 10.18677/EnciBio 2018A54

\begin{abstract}
RESUMO
Um dos maiores entraves da agricultura é a perda de produtividade devido ao ataque de pragas e doenças. A maior parte dos danos fitossanitários são provenientes de doenças com etiologia fúngica e a fruticultura é uma das atividades agrícolas mais suscetíveis ao ataque de doenças fúngicas. Na agricultura familiar é comum a atividade da propriedade ser voltada ao cultivo de frutas e legumes, por apresentar um ótimo rendimento em pequenas áreas. Por definição, emprega mão de obra familiar e é dependente da atividade para o próprio sustento, e na maior parte das vezes tem pouco ou nenhum acesso à tecnologia e assistência técnica. Por esse motivo o maracujazeiro pode ser uma opção altamente viável para agricultura familiar ao oferecer um retorno rápido, seguro e por absorver muita mãode-obra. Como a maioria das frutíferas, o maracujá está muito suscetível ao ataque de pragas devido as condições climáticas e o pouco uso de tecnologias de cultivo. A presença de doenças de etiologia fúngica nessas propriedades merecem maior atenção por promover danos além dos fatores agronômicos convencionais e atingir aspectos socioeconômicos. Por esse motivo a preocupação em levantar informações sobre manejo fitossanitário que possam apoiar pequenas propriedades é fundamental para fortalecer a atividade familiar. Esse trabalho se propôs a avaliar a incidência de doenças de etiologia fúngica no maracujazeiro em pequenas propriedades da região de alta floresta e elucidar os entraves que facilitam a disseminação de doenças do maracujazeiro na região.
\end{abstract}

PALAVRAS-CHAVE: agricultura familiar, etiologia fúngica, Maracujá.

\section{INCIDENCE OF PASSION FRUIT (Passiflora edulis sp.) fungal diseases in family farming of Alta Floresta-MT country}

\begin{abstract}
One of the biggest hindrances of agriculture is the loss of productivity due to pest attack. Most of the phytosanitary damage comes from diseases with fungal etiology, and fruit growing is one of the most susceptible agricultural activities to the attack of fungal diseases. In family farm, it is common for the activity of the property to be
\end{abstract}


focused on the cultivation of fruits and vegetables, because it presents an excellent yield in small areas. By definition, it employs family labor and is dependent on activity for its own sustenance, and in most cases has little or no access to technology and technical assistance. For this reason passion fruit can be a highly viable option for family farming by offering a quick, safe and labor-intensive return. Like most fruits, passion fruit is very susceptible to pest attack due to weather conditions and poor use of cropping technologies. The diseases of fungal etiology presence in these properties deserve greater attention for promote damages beyond conventional agronomic factors and to reach socioeconomic aspects. For this reason, the concern to raise information about phytosanitary management that can support small properties is fundamental to strengthen family work. The objective of this study was to evaluate the incidence of fungal etiology diseases in passion fruit in small properties in the high forest region and to elucidate the barriers that facilitate the spread of passion fruit diseases in the region.

KEYWORDS: Passion fruit, fungal etiology, family farming

\section{INTRODUÇÃO}

Alguns autores expõem relatos que as origens de espécies comerciais comestíveis de maracujá se deram nas imediações das florestas tropicais da américa do sul e região amazônica do Brasil e possivelmente no Paraguai e norte da Argentina (WIJERATNAM et al., 2016). Esse importante desenvolvimento se deve as favoráveis condições ambientais oferecidas nas regiões tropicais e subtropicais. Existem cerca de 420 espécies de Passifloraceas na natureza e no Brasil, cerca de 150 espécies, sendo que aproximadamente 60 são comestíveis. As espécies de maracujá mais comumente cultivadas no país maracujá azedo (Passiflora edulis Sims), apresentam características fenológicas que resultam em safras sazonais nas regiões Sul, Sudeste e Centro-Oeste (ESASHIKA et al., 2018).

O maracujá amarelo se destaca como principal representante da fruticultura brasileira, sendo destaque também no setor em exportações e consumo interno. $O$ Brasil é o maior produtor, maior consumidor e um dos principais exportadores de suco (CAVALCANTE et al., 2012). O mercado consumidor interno está cada dia mais exigente e a adequação da fruticultura as exigências, não só desse mercado devem ser atendidas, mas principalmente do mercado externo, onde os padrões de qualidade estão além da aparência visual. Segundo Marcelo et al. (2015), além da produtividade, a qualidade dos frutos é também de alta importância, determinando a aceitação do produto e influenciando diretamente no preço obtido em sua comercialização.

A garantia de origem é um pré-requisito básico para importar e os frutos devem ter qualidade sanitária, no que diz respeito a contaminantes biológicos e resíduos químicos. Dentre os fatores que colocam a fruta com baixa credibilidade diante dos mercados internacionais são injurias causadas por doenças graves que afetam a cultura do maracujazeiro, inviabilizando a sua produção sob o ponto de vista econômico, fazendo com que ela adquira caráter itinerante (BOTELHO et al., 2016). A região central brasileira compreendendo os estados de Mato Grosso do Sul, Mato Grosso, Goiás, Tocantins, Minas Gerais e o Distrito Federal, também vem optando pela fruticultura, na crista da onda diversificadora que varre o país e, dentro dela, está o maracujazeiro, que vem se constituindo uma opção importante (RUGGEIRO, 1998).

O cultivo do maracujazeiro no estado de Mato Grosso vem em crescimento acelerado, passou de um insignificante número estatístico de produtividade para um 
dos maiores produtores da fruta nacionalmente. É de grande relevância citar o caráter social da cultura do maracujá, haja vista ser ela uma frutífera cultivada predominantemente em pequenos pomares, em média de 1 a 4 ha. Sendo considerada uma cultura que expressa alta importância econômica para pequenas propriedades, alcançando bons índices de distribuição de renda ao logo do ano e apresentando alto poder comercial de frutas frescas (ARAÚJO et al., 2013).

$\mathrm{Na}$ região de Alta Floresta, o maracujazeiro é uma importante cultura explorada por pequenos produtores, sendo que muitos não têm acesso a informações referentes aos tratos culturais e cuidados necessários para assegurar uma boa produtividade. Com o desenvolvimento da cultura na região nos últimos anos, houve um aumento considerável na área cultivada sem a preocupação de realizar os cuidados necessários para evitar a entrada e disseminação de patógenos. Atualmente se faz necessário analisar as ocorrências e disseminações de fungos fitopatogênicos; relacionar com tratos culturais e fatores externos; e indicar práticas de manejo para diminuir a incidência de doenças causadas por fungos na cultura do maracujazeiro em pequenas propriedades. Assim sendo, o objetivo teve trabalho foi avaliar a incidência de doenças de etiologia fúngica no maracujazeiro na vila rural I, no Município de Alta Floresta-MT.

\section{MATERIAL E MÉTODOS}

O município de Alta floresta localiza-se ao extremo norte do Estado do Mato Grosso, na mesorregião 127 e microrregião 519. A área urbana de Alta Floresta está situada (098529 S; 568069 W, alt. 288 m) a 800 km de Cuiabá, a capital do estado de Maro Grosso (FOSTIER et al., 2015).

O clima é definido pela classificação de Koppen adaptado por Alvares et al. (2013) como tropical chuvoso, com duas estações bem definidas: verão chuvoso e inverno seco (am). A temperatura da região varia entre $20^{\circ}$ a $38^{\circ} \mathrm{C}$, tendo em média $26^{\circ} \mathrm{C}$. Com clima quente e úmido com quatro meses seco, suas principais características são as elevadas temperaturas podendo chegar a $45^{\circ} \mathrm{C}$, e sua pluviosidade pode atingir médias muitos elevadas, superiores a $2750 \mathrm{~mm}$.

O levantamento dos fungos fitopatogênicos que incidem na espécie Passiflora edulis sp., foi realizado em propriedades da vila rural 1 que cultivam o maracujazeiro. Para realização da pesquisa foram visitadas propriedades da comunidade Vila Rural 1, localizadas a $8 \mathrm{~km}$ do núcleo urbano de Alta Floresta. Das 160 chácaras, constatou-se que cinco produzem maracujá comercialmente. Para melhor organização foram denominadas como propriedades "A", "B", "C", "D", "E".: sendo distribuídas em nível de produção da seguinte maneira: propriedade $A: 200$ plantas com idade de dois anos; B: 200 plantas com idade de dois anos; C: 50 plantas com oito meses; D: 60 plantas com dois anos de idade; e propriedade E: 80 plantas com um ano de idade.

Nessas áreas foram coletados materiais biológicos sintomáticos para a constatação e a identificação do agente etiológico da doença em laboratório. Foram coletadas amostras de materiais sintomáticos de cada uma das cinco propriedades produtoras. A coleta desses materiais foi realizada in loco, no mês de outubro.

As amostras foram coletadas com o auxílio de tesoura de poda devidamente desinfetada e acondicionadas de forma asséptica em sacos plásticos para não haver contaminação. Foi feita a identificação de cada amostra, constando informações como: parte vegetal coletada e número da amostra (Figura 1). 


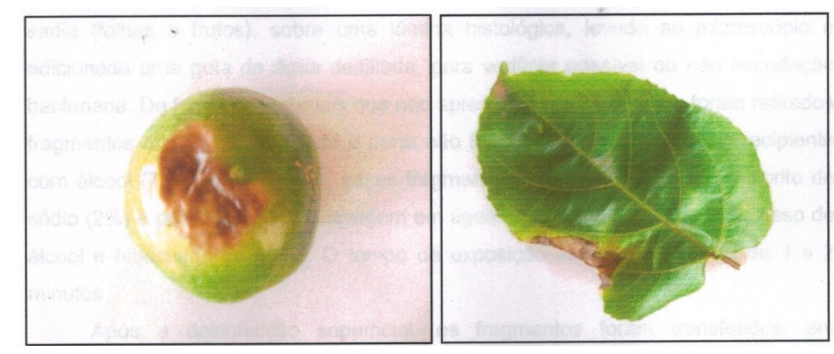

FIGURA 1. Amostra de material biológico sintomático em maracujazeiro na vila rural 1, no município de Alta Floresta, Mato Grosso. Fonte: autores.

As informações necessárias para relacionar a incidência de doenças fúngicas no maracujazeiro com manejo e os tratos culturais feito pelos proprietários foram obtidas por meio de entrevistas, observações in loco e um questionário semiestruturado aplicado aos produtores para obtenção de informações a respeito do manejo cultural, como: localização; data da coleta; número de plantas; idade do plantio; procedência da semente; realização de práticas culturais (adubação, irrigação, poda, controle fitossanitário; sistema de condução; culturas intercalares e adjacentes).

O procedimento para o isolamento dos agentes etiológicos foi feito em diversas etapas, seguindo os princípios Bergamin Filho et al. (1995) e Romeiro (2001) com adaptações. A primeira etapa constituiu-se na lavagem dos materiais biológicos; foram secos com papel absorvente, em seguida retirados pequenos fragmentos de tecido da região limítrofe entre a área lesionada e a área sadia (folhas e frutos), sobre uma lâmina histológica, levada a microscópio e adicionada a uma gota de água destilada, para verificar possível ou não exsudação bacteriana.

De todos os materiais que apresentaram exsudação, foram retirados fragmentos com partes lesionadas e não lesionadas, colocando em recipientes com álcool a 70\%. Em seguida, esses fragmentos foram imersos em hipoclorito de sódio $2 \%$ e por último a tríplice lavagem em água destilada para retirar o excesso de álcool e hipoclorito de sódio. O tempo de exposição em cada etapa foi de um a dois minutos.

Após a desinfecção superficial, os fragmentos foram transferidos em condições assépticas dentro da câmara de fluxo laminar, para placas de petri, contendo como meio de crescimento o BDA (batata, dextrose e ágar). Em seguida, as placas foram incubadas em câmara de germinação a uma temperatura de $25^{\circ} \mathrm{C}$, com fotoperíodo de $12 \mathrm{~h}$, por um período de sete a 14 dias.

Após o período de incubação de sete dias, as estruturas vegetativas e reprodutivas foram observadas e analisadas por meio de microscópio óptico e fotomicrografados utilizando os sistemas de imagens ACDSee acoplado ao microscópio. As lâminas foram preparadas utilizando a fita adesiva com as amostras e corante azul de algodão com lactofenol. Posteriormente com o auxilio da chave de classificação de Barnett; Hunter, (1972), e Menezes et al. (2004), foram feitas as identificações.

\section{RESULTADOS}

Diante das informações obtidas com o questionário devidamente preenchido a partir de entrevistas com os produtores constatou-se que na maior 
parte das propriedades visitadas, o cultivo do maracujazeiro não está seguindo um manejo fitossanitário, com a finalidade de prevenir a entrada e disseminação de patógenos, dentro da área de cultivo (Figura 2).
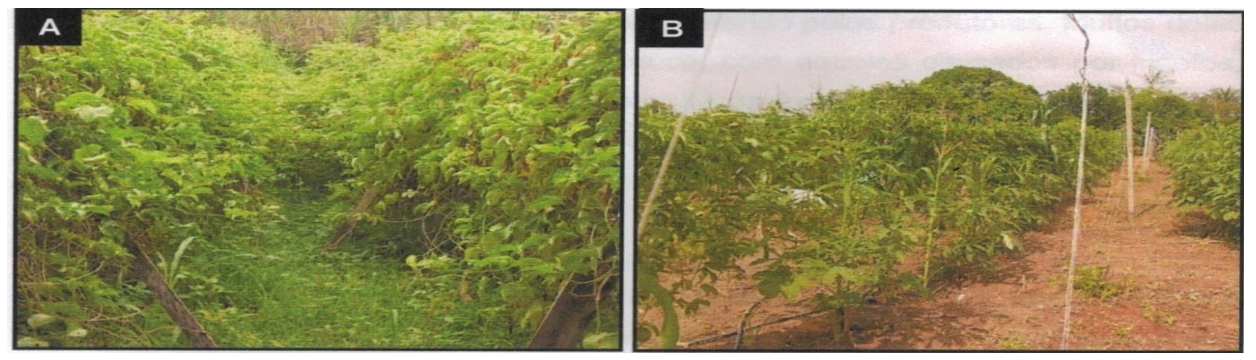

FIGURA 2. Propriedades sem o controle de tratos culturais (A), com tratos culturais recomendados $(B)$. Fonte: autores.

Foi observado que o uso de capina manual, para o controle de plantas espontâneas, é comum entre a maioria dos produtores de maracujá (Figura 3), prática de muita importância, já que reduz efeitos alelopáticos de plantas daninhas sobre a cultura, que eventualmente possa acontecer e deixar o maracujazeiro susceptível a doenças. A retirada de plantas invasoras também pode impedir que fungos fitopatogênicos referentes à cultura, possam sobreviver em hospedeiros alternativos.

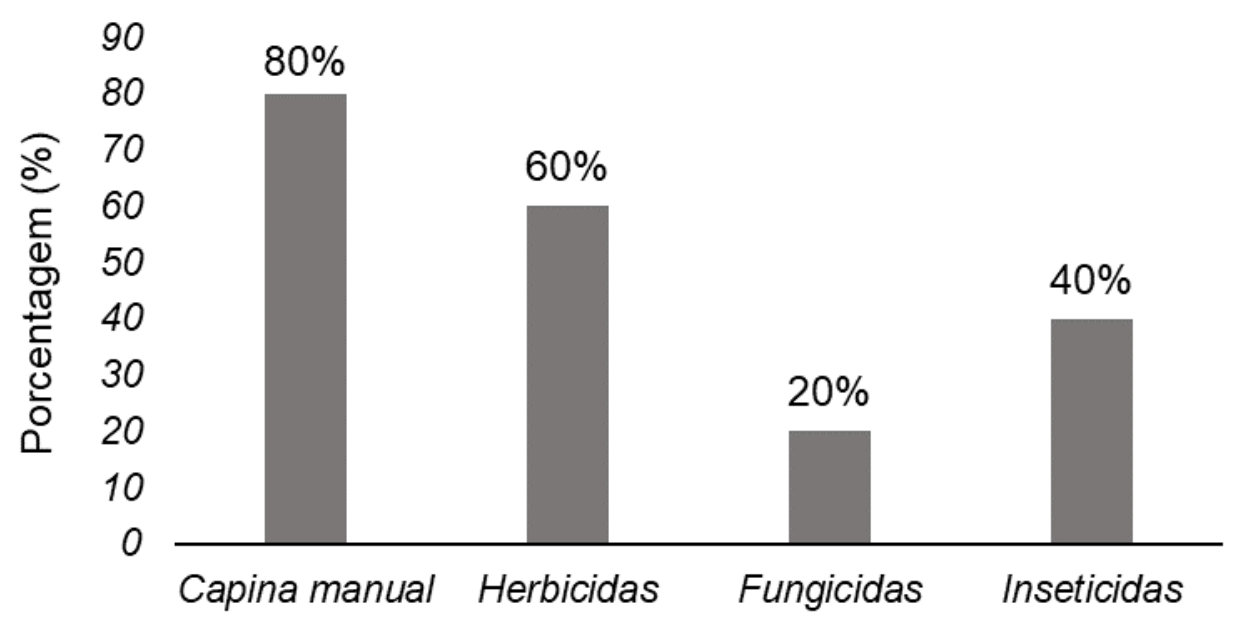

\section{Controle Fitossanitário}

FIGURA 3. Perfil do controle fitossanitário realizado pelos produtores de maracujá na vila rural 1, município de alta floresta MT

De acordo com Ferreira et al., (2015) fungos habitantes do solo colonizam os vasos da planta por meio de pequenos ferimentos ou aberturas naturais nas raízes, causando obstrução do xilema e morte da planta. Portanto deve se levar em consideração que a distribuição radicular do maracujazeiro é superficial, no entanto o manejo incorreto da capina manual, por uso inadequado de ferramenta pode danificar a base caulinar e o sistema radical da planta, causando ferimentos, servindo como porta de entrada direta para fitopatógenos de etiologia fúngica.

A desinfecção das ferramentas utilizadas para realização desse trato cultural não foi observada em nenhuma das propriedades visitadas, já que a mesma é 
utilizada para todas as outras culturas das propriedades favorecendo a disseminação de fungos fitopatogênicos dentro da área de cultivo.

Foi verificado informalmente entre os produtores, que de todos os problemas fitossanitários encontrados, os entraves fitopatológicos são os últimos em ordem de importância pelos mesmos. Observa-se no trabalho realizado por Tavanti et al. (2016) que no ano de 2011, foram constadas 48 marcas de fungicidas entre as 193 comerciais de agrotóxicos comercializados em Alta Floresta, resultando no consumo de 24,87\%. Essa taxa sofreu uma queda de 7,12\% no intervalo de 2012 a 2014. Nesse período foram comercializadas 11 marcas de fungicidas entre as 62 marcas de agrotóxicos comercializados em Alta Floresta, resultando uma queda no consumo de $17,75 \%$. O baixo uso de pesticidas para o controle de fungos fitopatogênicos se deve ao fato da ausência de assistência técnica e ao manejo eficiente de aplicação do produto, já que o único produtor dessa cultura dentre os cinco das regiões avaliadas que faz o uso de fungicida, relatou que o produto aplicado não diminuiu o agravamento da doença em sua propriedade.

Com a falta de assistência técnica o controle de inseto-praga no maracujá, em relação ao controle fitopatológico e mais preferido pelos produtores. Muitos deles confundem danos causados por fitopatógenos, com aqueles causados por insetos, fazendo com que a maioria opte pelo controle de insetos-praga, ignorando quase que por completo o controle de doenças. Deve-se ressaltar que o fator financeiro relatado pelos produtores, também faz parte dos entraves para um controle fitopatológico adequado.

Em nenhuma propriedade, provavelmente por falta de informações agronômicas por parte dos produtores, foi observado o controle de entrada e saída de pessoas e animais, que é um fator determinante para disseminação de doenças fitopatogênicas, dentro e fora das áreas cultivadas com maracujá.

A informações dos tratos culturais podem ser observados na Figura 4. Com relação ao uso de irrigação na cultura de maracujá, poucos produtores fazem uso desse tipo de tecnologia, alegando falta de recurso financeiro. Se por um lado o uso de irrigação aumenta a eficiência de produtividade da planta, em contrapartida pode criar microclima propícios para o desenvolvimento de fungos fitopatogênicos, se não for bem manejado.

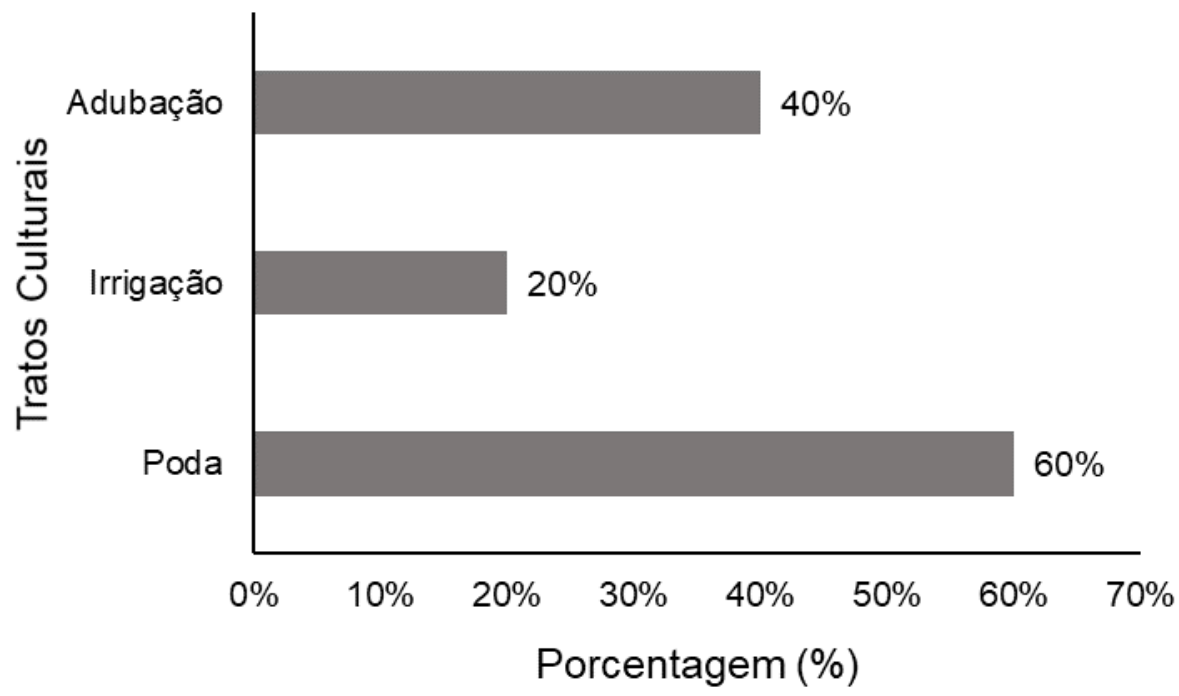

FIGURA 4 - Perfil dos tratos culturais realizados pelos produtores de maracujazeiro na vila rural I, no município de Alta Floresta. 
Os cuidados devem ser maiores com relação ao sistema de aspersão convencional e aspersão localizada, por criarem ambientes com temperatura e umidade ideal para o desenvolvimento de varias doenças de etiologia fúngica. $O$ único produtor das regiões avaliadas (propriedade E) que utiliza essa tecnologia, não tem muitos problemas fitopatogênicos relacionados com irrigação, pois este faz uso com sistema de irrigação localizada por gotejamento. Adicionalmente, o gotejamento tem a vantagem de não contribuir para a formação de um microclima úmido transitório no interior da cultura, pois a parte aérea da planta não é molhada, reduzindo assim os riscos de incidência de doenças (CABRAL et al., 2013).

De todas as cinco propriedades que foram feitas amostragem, as propriedades "A",'B" e "E", realizam operação de poda (Figura 04). De acordo com a Embrapa (2018), o intenso crescimento da planta estabelece o excesso de massa vegetativa favorável ao desenvolvimento de pragas e doenças. Mesmo assim não suficiente para impedir o aparecimento do fungo colltotrichum $\mathrm{sp}$., identificado nas propriedades "C" e "E" causador da antracnose, que segundo De Brito et al. (2017), trata se de uma doença de grande importância, sendo considerada a que mais ocorre no cultivo do maracujá, por atacar a parte aérea das plantas em qualquer estágio vegetativo. Já que as condições climáticas no mês de outubro no município de Alta Floresta são chuvas frequentes e abundantes com temperaturas médias de $28^{\circ} \mathrm{C}$, acaba por favorecer o ataque de patógenos e ocorrência de epidemias.

No quesito adubação (Figura 4), os únicos que fazem o uso de adubo são os proprietários "E" e "B", ambos com formulação NPK (04-14-08). Não foi possível relacionar diretamente a incidência de fungos fitopatogênicos em culturas de maracujá adubados e não adubados, porém pode se afirmar que as plantas com melhor estado nutricional tendem ataques fitopatogênicos com menores severidade. Alguns estudos mostram que determinada fonte de nutriente estimula diretamente a indução de resistência na planta como o trabalho de Spolti et al. (2015) que constataram a influência dos fosfitos no controle da podridão olho de boi em maças.

Doenças como a antracnose, murcha de fusarium e verrugose, que são as mais importantes do maracujazeiro, são causadas por fungos em que os principais meios de disseminação são por via de sementes e mudas infectadas. Uma das medidas de controle mais utilizadas para evitar a disseminação de fungos fitopatogênicos em áreas de cultivo é o uso de sementes e mudas livre de patógenos. Segundo Brugnara (2014), comprar mudas traz o risco de introdução de patógenos como virose e fungos, importados para a propriedade de maneira invisível pelo fato do produtor desconhecer sintomas inicias. Isso não foi observado na maioria dos produtores que cultivam maracujá. De acordo com o questionário realizado, apenas $20 \%$ dos produtores adquiriram sementes de boa qualidade (Figura 05). 


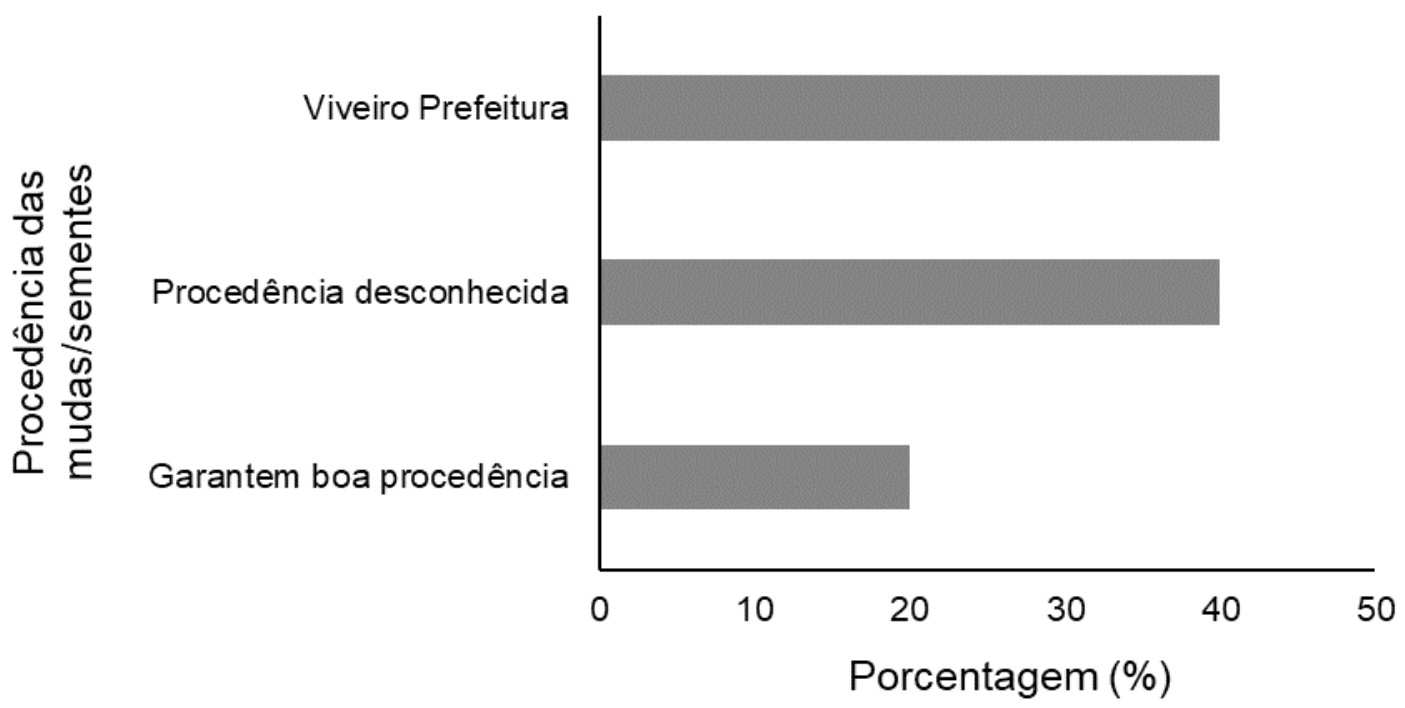

FIGURA 5. Procedência das sementes e mudas utilizadas pelos produtores de maracujazeiro na Vila Rural I, no município de Alta Floresta - MT. 2009.

Nos demais produtores observou-se, por ausência de informação, uma falta de preocupação em relação à aquisição de sementes e mudas, já que muitos nem sabiam ao menos procedência das sementes. Os produtores que adquiriram sementes do viveiro da prefeitura municipal de Alta Floresta (40\%) não têm uma garantia sobre a fitossanidade das mesmas, já que, segundo Oliveira (2009), as mudas provenientes do viveiro da prefeitura, não tem uma seleção minuciosa para separar plantas que exibiam sintomas de doença nem plantas que apresentavam algum sintoma de deficiência nutricional ou anomalia, contribuindo diretamente com a incidência de doenças fúngicas na região avaliada.

A partir dos resultados obtidos com a análise feita em laboratório, nas cinco propriedades, onde foram coletadas as amostras de materiais sintomáticos, identificou-se os seguintes fungos fitopatogênicos: Colletotrichum sp., Fusarium sp., Rhizoctonia sp., Aspergilus sp., Curvulan'a sp., Geotrichum sp., He/minthosporium $s p .$, Phytomices sp., Phoma sp., e Pennicilium $s p$.

$\mathrm{Na}$ propriedade "A" identificaram-se três amostras com Fusarium sp., uma amostra com Colletotrichum sp., e uma amostra com Rhizoctonia sp. Na propriedade "B" identificaram-se quatro amostras com Fusarium sp., uma amostra com Colletotrichum sp., uma amostra com Cladosporium sp., e uma amostra com Geotrichum sp (Figura 6). 


\section{Propriedade A \\ - Fusarium sp. $\quad$ Colletotrichun sp. \\ - Rhizoctonia $\mathrm{sp}$}

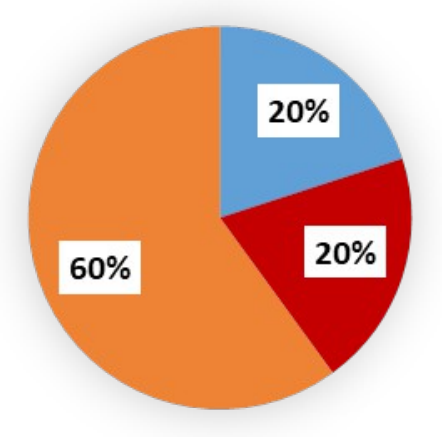

\section{Propriedade B}

- Fusarium sp. $\quad$ Colletotrichun $\mathrm{sp.}$

¿ Cladosporium sp. $₫$ Outros

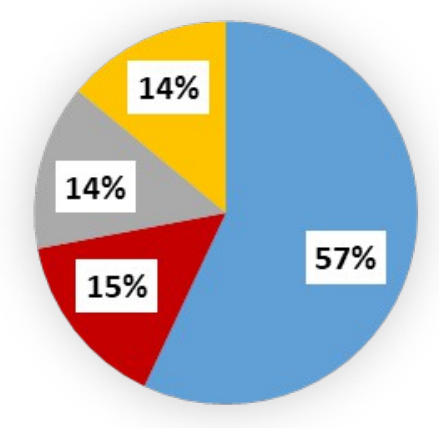

FIGURA 6. Incidência de fungos fitopatogênicos nas propriedades "A" e "B" na Vila Rural I, em Alta Floresta - MT. 2009.

Na propriedade " $\mathrm{C}$ " identificaram-se quatro amostras com Fusarium sp., três amostras com Colletotrichum sp., uma amostra com Curvularia sp. e uma amostra com Phytomices sp. (Figura 7).
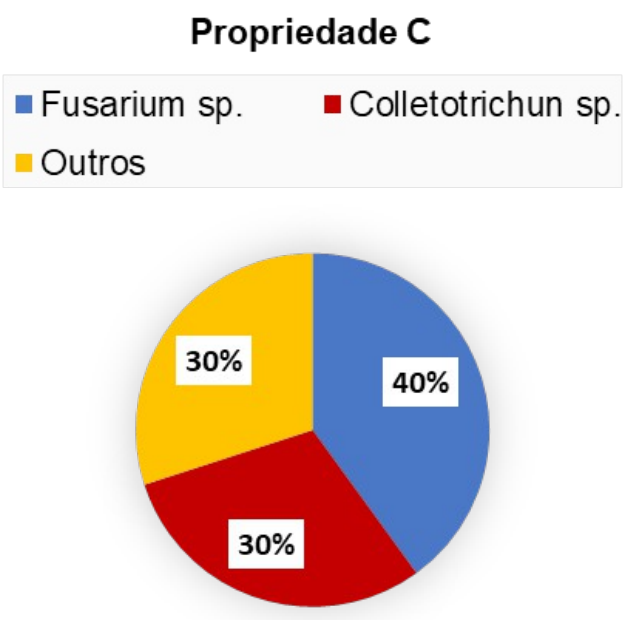

FIGURA 7. Incidência de fungos fitopatogênicos na propriedade "C" na Vila Rural I, em Alta Floresta - MT.

Na propriedade "D" identificaram-se duas amostras com Colletotrichum sp., duas amostras com Rhizoctonia sp., uma amostra com " Aspergilus sp., uma amostra com Pennicilium sp., uma amostra com Phytomices sp. e duas amostra com Geotrichum sp. Na propriedade "E" identificou-se uma amostra com Fusarium sp., duas amostras com Colletottrichum sp., uma amostra com Curvularia sp., uma amostra com Helminthosporium sp., uma amostra com Phytomices sp. e uma amostra com Phoma sp. (Figura 8). 
Propriedade D

- Colletotrichun sp. - Rhizoctonia sp

Outros

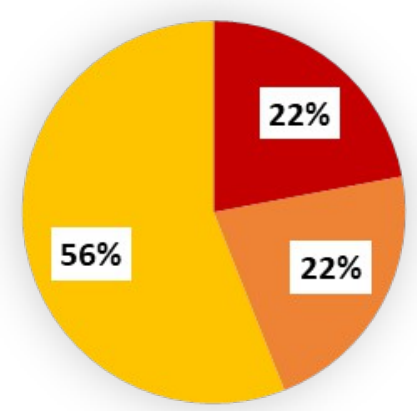

\section{Propriedade E}

- Fusarium sp. $\quad$ Colletotrichun $\mathrm{sp}$.

- Outros

FIGURA 8. Incidência de fungos fitopatogênicos nas propriedades "D" e "E" na Vila Rural I, em Alta Floresta - MT. 2009.

O fungo Fusarium sp., causador do damping-off, mela e murcha de fusarium, foi constatado nas propriedades "A", "B", "C" e "E" e faz parte de $32 \%$ dos fungos fitopatogênicos identificados em todas as áreas avaliadas (Figura 11). Resultado diferente obtido por Oliveira (2009), que ao analisar a incidência de doenças de etiologia fúngica no maracujazeiro na vila rural II, constatou o fungo Fusarium sp., somente em uma propriedade. Essa diferença ocorreu, devido à época de coleta do material sintomático, que ocorreu no mês de outubro (período das águas) e pode ter favorecido o aparecimento da doença. Este fungo foi identificado com maior percentual na propriedade "A", encontrado em $60 \%$ das amostras. Nessa propriedade observou-se ausência total de um manejo fitossanitário e alta quantidade de restos culturais de culturas intercalares, o que pode ter influenciado diretamente na maior incidência. A menor incidência do patógeno (14\%) foi observada na propriedade " $E$ ", nesta a área de cultivo está praticamente ausente de restos vegetais e são efetuados os tratos culturais como poda, adubação, irrigação localizada, controle de plantas invasoras (Figura 9), que acaba desfavorecendo a disseminação do fungo na área de cultivo.
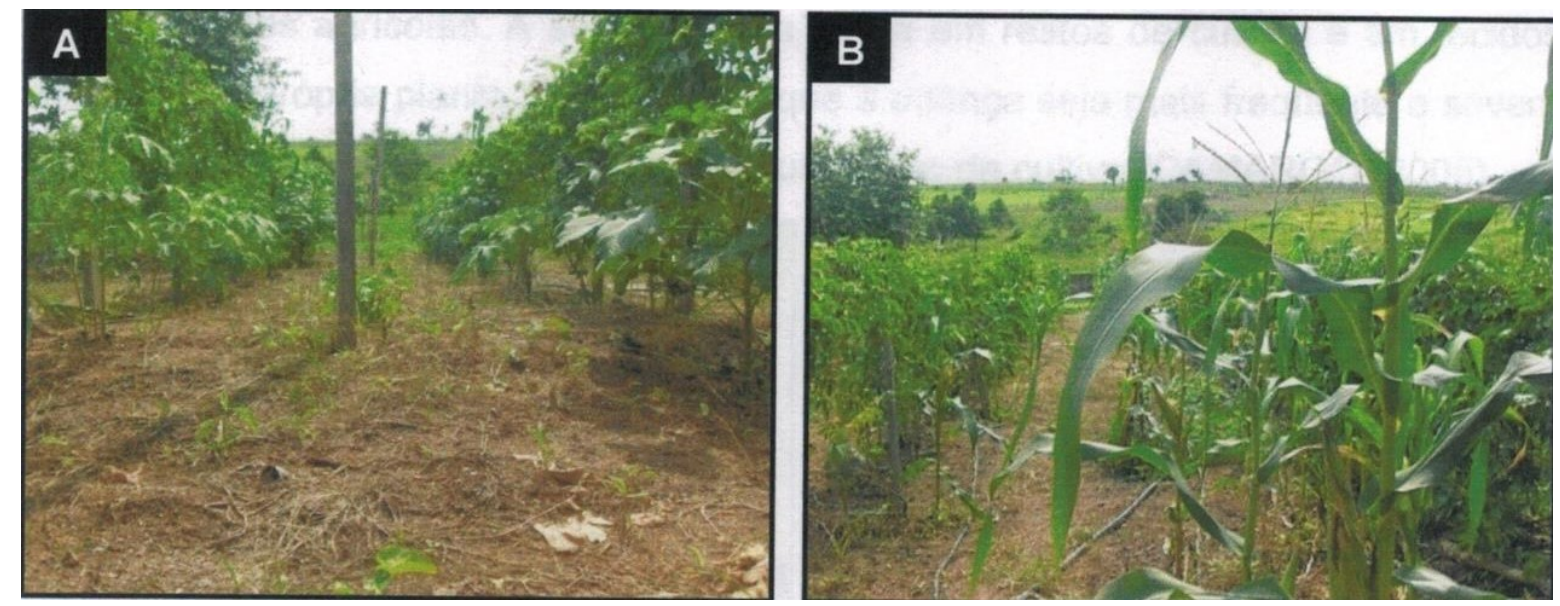

FIGURA 9. Propriedade "E", ausente de restos vegetais (a), e maracujazeiro em consorcio com o milho na vila Rural (b), no município de Alta Floresta - MT. 2009. Fonte: autores. 
A produção de estruturas de resistência (clamidósporos), acompanhada de sua elevada gama de hospedeiros que estes patógenos podem infectar, dificulta o manejo destes fungos podendo sobreviver em resíduos orgânicos em decomposição, restos vegetais e solos contaminados ao longo de muitos anos (PORTO et al., 2016). O período chuvoso na região de Alta Floresta acaba contribuindo com a disseminação da doença no campo, já que de acordo com Camargo (2005), altas temperaturas e umidades relativas são favoráveis ao aparecimento da doença no campo.

Dentre os fungos fitopatogênicos identificados nas amostras, o fungo Colletotrichum sp., causador da antracnose (Figura 10), uma das principais doenças na cultura do maracujazeiro, foi constatado em todas as propriedades, representando $24 \%$ do total de fungos fitopatogênicos identificados (Figura 11), resultado semelhante obtido por Oliveira (2009), em seu trabalho sobre levantamento de doenças fúngicas na Vila Rural II.

Entre as propriedades analisadas, a que apresentou maior incidência de Colletotrichum sp., foi a propriedade " $\mathrm{C}$ ", devido ao manejo fitossanitário incorreto e restos culturais presentes no solo associados principalmente as condições climáticas na região, que segundo Camargo (2005), a ocorrência de epidemia é favorecida por alta umidade, especialmente com chuvas frequentes e abundantes e temperatura média entre 26 e $28^{\circ} \mathrm{C}$. Observou-se, nas propriedades " $B$ ", " $C$ " e " $D$ " com incidência desse patógeno, partes vegetativas da planta do maracujazeiro, como frutos e ramos caídos no chão, servindo de fonte de inoculo para o próximo ciclo da doença na área de cultivo. A disseminação do patógeno ocorre através de sementes, respingos de chuva, insetos e implementos agrícolas. A sobrevivência se dá em restos de cultura e em tecidos afetados na própria planta, fazendo com que a doença seja mais frequente e severa em uma determinada área a partir do segundo ano de cultivo (CAMARGO, 2005).
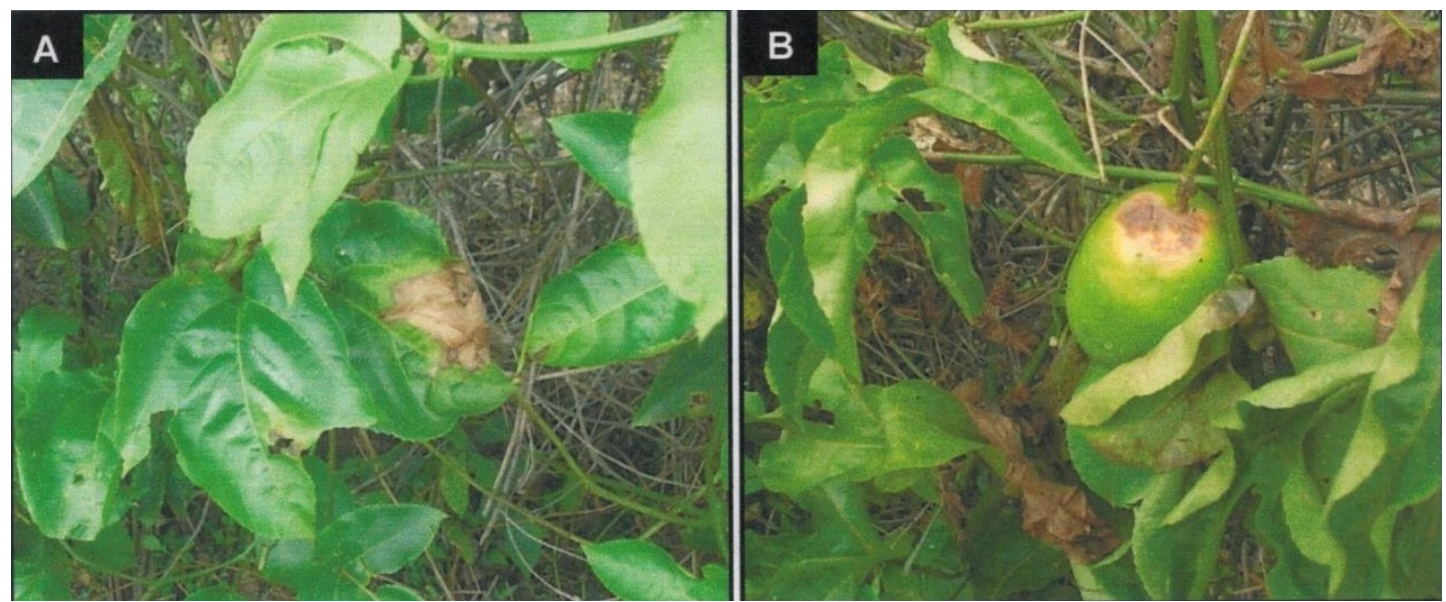

FIGURA 10. Folha (a) e fruto (b) com sintomas de antracnose causado pelo fungo, Colletotrichum gloesporioides, em maracujazeiro na Vila Rural I, no município de Alta Floresta — MT. 2009. Fonte: autores.

O fungo Rhizoctonia sp., causador da mela ou Daping-off, foi constatado apenas na propriedade "A" e " $D$ ". O controle dessa doença se faz no manejo adequado da sementeira, porém muitos produtores não realizam as práticas adequadas na obtenção da muda, fato que colabora para a disseminação da doença no plantio. Nas propriedades em que foram constatados o patógeno, as sementes foram obtidas do viveiro da prefeitura, no qual não apresenta controle fitossanitário ENCICLOPÉDIA BIOSFERA, Centro Cientifico Conhecer - Goiânia, v.15 n.27; p. 76 2018 
(OLIVEIRA, 2009) e pode ter sido a causa do aparecimento do fungo. A doença é particularmente severa sob condições de umidade excessiva, causando um rápido encharcamento nos tecidos tenros da planta no solo, que entram em colapso, provocando a murcha-das-folhas, o tombamento e a morte das plantas (EMBRAPA, 2018).

A verrugose, causada pelo fungo Cladosporium herbarum, é uma das doenças mais comuns observadas na região, porém foi identificada apenas na propriedade "B" com baixa incidência no campo. Esse fato se deve,aos seguintes aspectos: $C$. herbarum é um fungo saprófito capaz de sobreviver nos restos culturais de plantas contaminadas, apresenta processo de infeção favorecido em ambientes com elevada umidade relativa do ar e temperaturas amenas $\left( \pm 20^{\circ} \mathrm{C}\right)$ (ASCARI et al., 2016).

As condições climáticas do município de Alta Floresta no período de coleta das amostras eram chuvas frequentes e temperaturas acima de $26^{\circ} \mathrm{C}$, nessas condições os sintomas ocorreram somente nos frutos. Com o período de comercialização do maracujá, acabou reduzindo consideravelmente amostras de materiais sintomáticos na área de cultivo, dificultando a visualização no campo. Em condições laboratoriais, as placas foram incubadas em câmara de germinação a uma temperatura de $25^{\circ} \mathrm{C}$, porém, como já foi citado, esta espécie de fungo se desenvolve em temperaturas entre $15^{\circ} \mathrm{C}$ e $22^{\circ} \mathrm{C}$, fato esse que acabou inibindo 0 crescimento e o desenvolvimento de estruturas de frutificação. $O$ trabalho realizado por Oliveira (2009), em propriedades da Vila Rural II, Alta Floresta - MT, não detectou a presença do fungo $C$. herbarum em maracujazeiros nas áreas avaliadas, apesar da doença estar sendo facilmente observada em frutos comercializados na região.

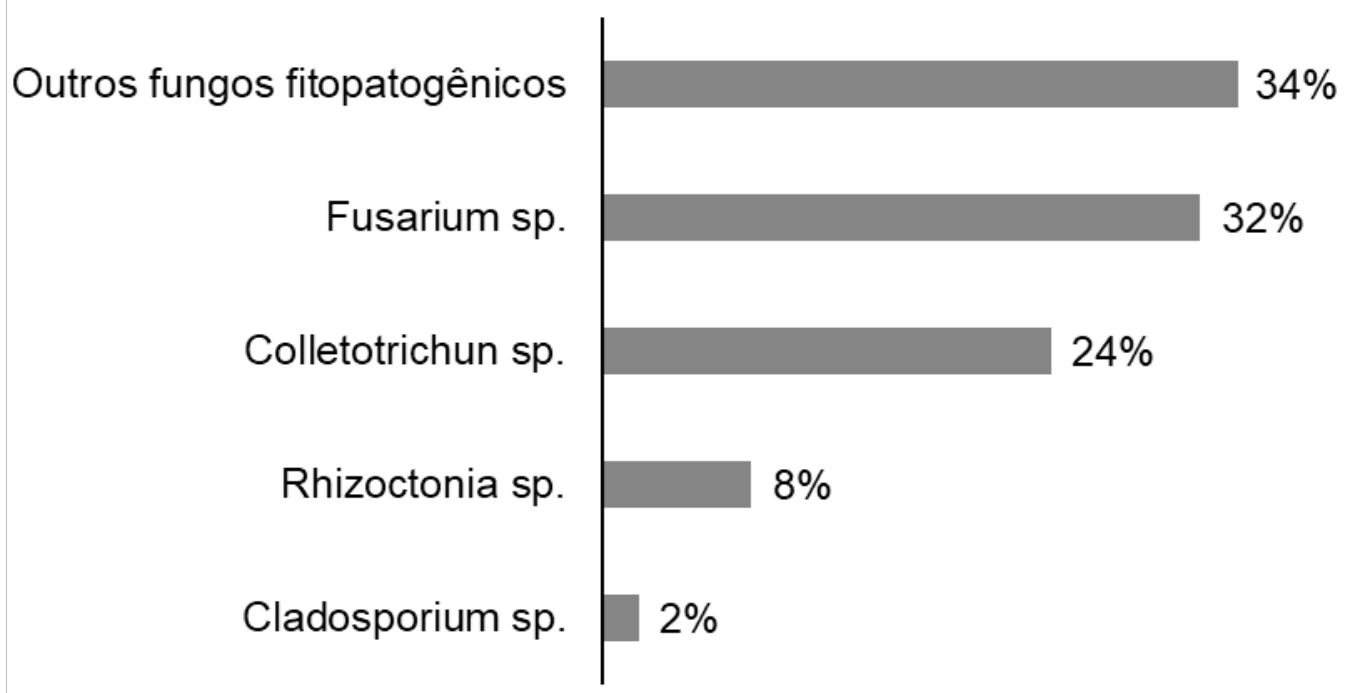

FIGURA 11. Percentual de fungos fitopatogênicos identificados em todas as áreas de maracujazeiros na Vila Rural I, no município de Alta Floresta - MT. 2009.

A presença de fungos fitopatogênicos de pouca importância no maracujá, mas que podem interferir na qualidade do produto, como Aspergilus sp., Curvularia sp., "Geotrichum sp., Helminthosporium sp., Phytomices sp., Phoma sp., Streptomices sp., e Pennicilium sp., se deve as culturas intercalares e consorciadas com o 
maracujazeiro (ASSUNÇÃO et al., 2015). Foi observado in loco a presença de culturas como abacaxi, abobora, banana, café, milho, cultivadas junto ao maracujazeiro sem um manejo fitossanitário adequado com as plantas consorciadas. Fatores como espaçamento, época de plantio, contato direto com outras culturas (Figura 12), não são levados em consideração pelos produtores, contribuindo diretamente com a presença desses fungos fitopatogênico na planta de maracujá.
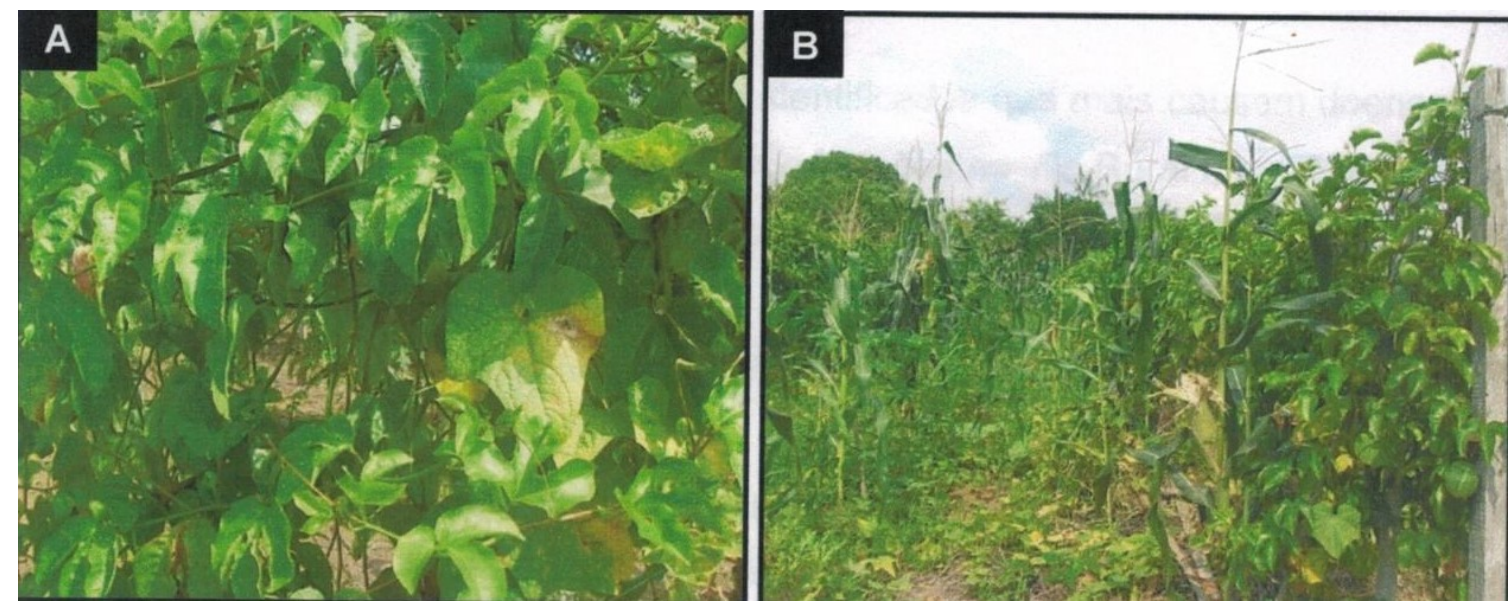

FIGURA 12. Maracujazeiro em contato direto com milho e abobora (b), na propriedade "E" na Vila Rural I, no município de Alta Floresta MT. 2009. Fonte: Dos autores.

Esses fatos mostram que a planta do maracujazeiro serve de ambientes para reprodução e disseminação para outros fungos que podem acometer em culturas intercalares ou consorciadas com o maracujá, necessitando de um manejo fitossanitário mais amplo e adequado.

\section{CONCLUSÕES}

Os patógenos de etiologia fúngica identificados que mais causaram doenças no cultivo do maracujazeiro nas pequenas propriedades na vila Rural I, em Alta Floresta foram os seguintes: Colletottichum sp, Fusarium sp., Rhizoctonia sp. e fungos de pouca importância como: Aspergilus sp., Curvularia sp., Geotrichum sp., Helminthosporium sp., Phytomices sp., Phoma sp., Streptomices sp., e Pennicilium $\mathrm{sp}$.

O baixo nível de tecnologia utilizado pelos pequenos produtores de maracujazeiro e a falta de informações agronômicas para um bom manejo fitossanitário é a principal causa da disseminação dos fungos fitopatogênicos dentro das propriedades avaliadas.

\section{REFERÊNCIAS}

ALVARES, C. A.; STAPE, J. L.; SENTELHAS, P. C.; DE MORAES, G. J. L.; SPAVOREK, GERD. Köppen's climate classification map for Brazil. Meteorologische Zeitschrift, v. 22, p. 711-728, 2013. Disponível em: <http://www.ingentaconnect.com/content/schweiz/mz/2013/00000022/00000006/art0 0008>. Doi: https://doi.org/10.1127/0941-2948/2013/0507

ASCARI, J. P.; MENDES, I. R. N.; SANTOS, E. S.; ARAÚJO, D. V.; LEMOS, V. L. J. et al. Levantamento de doenças da cultura da berinjela em assentamento rural no município de Tangará da Serra/MT. Nucleus, v. 13, p. 205-214, 2016. Disponível ENCICLOPÉDIA BIOSFERA, Centro Cientifico Conhecer - Goiânia, v.15 n.27; p. 78 2018 
em: $\quad$ <http://nucleus.feituverava.com.br/index.php/nucleus/article/view/1573>. Doi: http://dx.doi.org/10.3738/1982.2278.1573

ASSUNÇÃO, P. M.; KRAUSE, W.; DALLACORT, R.; DOS SANTOS, P. R. J.; NEVES, L. J. Seleção individual de plantas de maracujazeiro azedo quanto à qualidade de frutos via REML/BLUP. Revista Caatinga, v. 28, n. 2, 2015. Disponível em: $<$ https://periodicos.ufersa.edu.br/index.php/sistema>.

BARNET, H. L.; HUNTER, B. Illustrated genera of Imperfect Fungi. English, Book, Illustrated edition, 3rd. Edition. v. 241, 240p., 1972. Disponível em: < https://www.cabdirect.org/cabdirect/abstract/19721103191>.

BERGAMIN FILHO, A.; KIMATI, H.; AMORIM, L. (Ed.). Manual de fitopatologia: princípios e conceitos. 3. ed. São Paulo: Agronômica Ceres, v. 1, p. 811-817, 1995.

BOTELHO, S. C. C.; MIGUEL-WRUCK, D. S.; RONCATTO, G.; OLIVEIRA, S. S.; BOTELHO, F. M. et al. Qualidade pós-colheita de maracujá-amarelo em função de porta-enxertos e ambientes de cultivo. Comunicata Scientiae, v. 7, p. 504-512, 2016. Disponível em: <https://search.proquest.com/docview/1882046279?pqorigsite=gscholar $>$. Doi: 10.14295/CS. v7i4.1579

BRUGNARA, E. C. Cama de aviário em substratos para mudas de maracujazeiroamarelo. Revista Brasileira de Agroecologia, v. 9, p. 21-30, 2014. Disponível em: <http://revistas.abaagroecologia.org.br/index.php/rbagroecologia/article/view/15270/1 0658>. ISSN 1980-9735.

CABRAL, R. N.; MAROUELLI, W. A.; LAGE, D. A. C.; CAFÉ-FILHO, A. C. Septoria leaf spot in organic tomatoes under diverse irrigation systems and water management strategies. Horticultura Brasileira, v. 31, p. 392-400, 2013. Disponível em:<http://www.scielo.br/scielo.php?

pid=S010205362013000300009\&script=sci arttext $>$. Doi: 10.1590/S010205362013000300009

CAMARGO, L. E. A. Manual de Fitopatologia: Doenças da Plantas Cultivadas. vol.2. $4^{a}$ ed. Editora Agronômica Ceres Ltda. São Paulo-SP: 2005. 663p.

CAVALCANTE, I. H. L.; CAVALCANTE, L. F.; DOS SANTOS, G. D.; BECKMANNCAVALCANTE, M. Z. et al. Impact of biofertilizers on mineral status and fruit quality of yellow passion fruit in Brazil. Communications in soil science and plant analysis, v. $43, \quad$ n. 15, p. 2027-2042, 2012. Disponível em: $<$ https://www.researchgate.net/publication/267568327>. ISSN 2236 - 4420

DE ARAÚJO, H. F; COSTA, R. N. T.; CRISÓSTOMO, J. R.; SAUNDERS, L. C. U.; MOREIRA, O. C. Technical and economic indicators of the yellow passion fruit tree irrigated with underground water supply. Engenharia Agrícola, v. 33, p. 940-951, 2013. Disponível em: <http://www.scielo.br/scielo.php?pid=S010069162013000500006\&script=sci_arttext\&tlng=pt>. Doi 10.1590/S010069162013000500006. 
DE BRITO, R. S.; ALVES, W. F.;MOREIRA, J. G. V. Avaliação do efeito da inibição da antracnose do maracujazeiro com a utilização do óleo de Pupunha (Bactris gasipaes). South American Journal of Basic Education, Technical and Technological, $\quad$ v. $4,2017 . \quad$ Disponível em: http://revistas.ufac.br/revista/index.php/SAJEBTT/article/view/1425>

EMBRAPA - Empresa Brasileira de Pesquisa Agropecuária , Portal Embrapa, (Versão 3.52.0) p, 03, 2018. Disponível em: https://www.embrapa.br/mandioca-efruticultura/cultivos/maracuja.

ESASHIKA, D. A. S.; FALEIRO, F. G.; JUNQUEIRA, N. T. V. Phenology of the production of flowers and fruits of wild and hybrid species of the genus Passiflora. Revista Brasileira de Fruticultura, v. 40, p. 177-188, 2018. Disponível em: <http://www.scielo.br/scielo.php>. Doi http://dx.doi.org/10.1590/010029452018188

FERREIRA, R. B.; RODRIGUES. A. A. C.; MORAES, F. H.; CANDIDO E SILVA, E. K.; NASCIMENTO, I. O. Residuos orgánicos en el control de Fusarium oxysporum f. sp. passiflorae en maracuyá amarillo (Passiflora edulis f. flavicarpa). Acta Biológica Colombiana, v. 20, p. 111-120, 2015. Disponivel em: <https://revistas.unal.edu.co/index.php/actabiol/article/view/44720>.

FOSTIER, A. H.; MELENDEZ-PEREZ, J. J.; RICHTER, L. Litter mercury deposition in the Amazonian rainforest. Environmental pollution, v. 206, p. 605-610, 2015. Disponível em: <https://www.sciencedirect.com/science/article/pii/S0269749115300051>.Doi:10.101 6/j.envpol.2015.08.010

MENEZES, M.; ASSIS, S. M. P. Guia Prático para fungos fitopatogênicos. $2^{a}$ edição, imprensa universitária. UFRPE, Recife-PE, 2004. Disponível em: <http://www.scielo.br/scielo.php?script=sci_nlinks\&ref=000125\&pid=S1808$1657201200040001300024 \&$ Ing=es>.

OLIVEIRA, E. S. Levantamento de Etiologia fungica que incidem no maracujazeiro (Passiflora edulis Sims f. flavicarpa Degener) na Vila Rural " - Alta Floresta - MT. Alta floresta. Trabalho de Conclusão de curso (Graduação em Licenciatura plena em Ciências Biológicas) - Universidade do Estado de Mato Grosso. 2009. CD-ROM.

PORTO, M. A.F.; AMBRÓSIO, M. M. De Q.; DE FREITAS, F. C. L.; NASCIMENTO, S. R. C.; DA CRUZ, B. L. S. et al. Feijão-de-porco (Canavalia ensiformis) no controle da podridão radicular do meloeiro causada por associação de patógenos. Summa Phytopathologica, v. 42, n. 4, p. 327-332, 2016. Disponível em: $<$ http://www.ingentaconnect.com/content/doaj/01005405/2018/00000042/00000004/a rt00006>.Doi: https://doi.org/10.1590/0100-5405/2183

SPOLTI, P.; VALDEBENITO-SANHUEZA, R. M.; CAMPOS, A. D.; DEL PONTE, E. M. Modo de ação de fosfitos de potássio no controle da podridão olho de boi em maçã. Summa Phytopathologica, v. 41, n. 1, p. 42-48, 2015. Disponível em: <http://www.ingentaconnect.com/content/doaj/01005405/2015/00000041/00000001/a rt00007>. Doi: https://doi.org/10.1590/0100-5405/1982 
TAVANTI, T. R.; LEHBACH, H.; De OLIVEIRA, F. F.; TAKESHITA, V.; RIBEIRO, L. F. C. Clínica de Doenças de Plantas: uma ação da extensão universitária da Unemat em Alta Floresta. Revista Cultura \& Extensão UNEMAT, v. 1, p. 91-101, 2016. Disponível em: <https://periodicos.unemat.br/index.php/rceu/article/view/1141>. ISSN: $2448-2420$

WIJERATNAM, S. W. Passion Fruit. Encyclopedia of Food and Health. v. 23. p. 231-235, 2016. Disponível em: <http://dx.doi.org/10.1016/B978-0-12-3849472.00521-3>. Doi 10.1016/B978-0-12-384947-2.00521-3 